\title{
Effects of roof insulation on the thermal conditions of a medium scaled tropical enclosed giant freshwater prawn (Macrobrachium rosenbergii) hatchery
}

\begin{abstract}
This study was conducted to evaluate the effects of roof thermal insulation on the indoor thermal environment of an existing enclosed giant freshwater prawn hatchery in relation to human thermal comfort and the thermal requirement for optimal larval growth. A typical medium scaled enclosed hatchery in Ipoh, Malaysia was chosen for this study. Thermal performances of five thermal insulation materials installed on the roof of the building were studied using Integrated Environmental Solutions (IES) Virtual Environment software. Results showed no significant differences for indoor air temperatures reduction among the insulation materials. However, the installation of roof insulation gave a cooler indoor thermal environment and provided a suitable water temperature/ improved water thermal condition for the prawn larviculture. The study also suggested the aluminium foil was the best insulation for the partially transparent roof of the building.
\end{abstract}

Keyword: Enclosed prawn hatchery building; Roof insulation; Thermal comfort; Tropical 